\title{
ISOLATION OF SOME WOOD DECAYING FUNGI AND STREPTOMYCES AND THEIR EFFECTS ON SOME COMMERCIAL TIMBER SPECIES IN SRI LANKA
}

\author{
D T Boralessa, P Tissera and H S Amarasekera \\ University of Sri Jayewardenepura, \\ Nugegoda.
}

\begin{abstract}
Wood is subject to attack by werd inhabiting fungi in a varicty of environmental situations from the standing tree to the wood product in service. An investigation wats carried out to study the resistance of live commercial timber species namely Rubber (//e'vea brasilichsis).

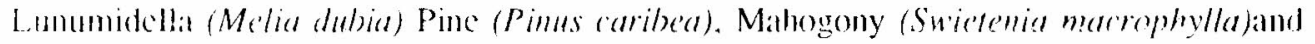
Teak (Terome sramdis) to lungal attack.
\end{abstract}

Four wood decaying fungal species were isolated from naturally infected woxd samples. Three species namely Triroderma sp., Mycelia sterilia and Streptomyce's sp. belonging to Deuteromycotina subdivision and Aspergille's sp. belonging to Ascomycotina subdivision were identified. These species were used to assess the initial decay of wood. Out of the four species tested Streptomyees sp. wals the most destructive fungal species.

The weight loss of timber was taken as parameter of decay. Wood species and the fungal species had a significant effect on the weight loss. The highest weight loss due to fungal altack was caused hy Sereptomyce's speries in all the limber species except in Lunumidella where Tricoderma sy. recorded the highest weight loss.

In Rubber, Lunumidellat and Pinus moisture gain was observed with fungal atlack while moisture loss was observed in controls. In Mahogany and Teak moisture gain due to lungal allack was negligible. Since these fungi caused a considerable damage at the initial stage of decay they can be grouped as primary decaying fungi in wood. 